\section{Polish Academy defends itself}

SIR - I am glad that you take an interest in science in Poland, but must ask you correct a number of mistatements in a recent article (Nature 364, 748; 1993).

The State Committee for Science Research $(\mathrm{KBN})$ was established not to "take over from the communist-controlled" Polish Academy of Sciences (PAN), but, in the interests of good organization and the more systematic financing of research, to replace both the State Committee for Science and Technology and the State Office for the Implementation of Science and Technology. There is no question of a transfer of power from PAN, which never enjoyed it.

In my opinion, it makes no sense at this stage to ask which of PAN, the universities and the state-controlled institutes used to be the most tightly controlled, but your article conflicts with the recently published report of the secret services that PAN used to be a haven for scholars expelled from the universities on political grounds.

Indeed, the secret report published in 1984 noted that PAN supported individuals who expressed both theoretical and practical opposition to the regime, "dominated" as the academy was by "hostile elements". (That is the opinion of Jan Krzysztof Frąckowiak, which you do quote.)

Perhaps the best proof of that is the composition of the Polish government before the elections in September. No fewer than four members of the government, including the prime minister, Hanna Suchocka, were members of PAN institutes.

We are proud that during the 40 years of PAN's existence, it held to the principle of conferring membership only on creative scholars, most of them not party members. Many of PAN's delicately expressed opinions were very different from party ideology. It is also relevant that PAN's 80 research institutes, employing only 8 per cent of Poland's scientists, have always enjoyed the highest ratings.

Many of its members have enjoyed cooperation with leading national academies and other scientific societies in 40 countries, enabling them to work in laboratories elsewhere and to carry out joint projects. During the past 15 years, of 4,100 researchers employed in PAN institutes, no fewer than 3,000 were awarded fellowships to attend British research institutes, thanks to agreements with the Royal Society and the British Academy. At the same time, several British researchers are foreign members of PAN.

The future of science in Poland depends on the creative activity of researchers supported by a rational science policy and not, as your article claims, on whether the
State Committee for Science Research will survive another change of government.

\section{Leszek Kuźnickì}

(President)

Polish Academy of Sciences,

Warsaw, Poland

\section{Testing for Alzheimer's}

SIR - Beneath the title of an advertisement in Nature (11 November 1993, facing page 129) headed "ApoE predicts Alzheimer" was the quotation "... a common marker for a devastating and frightening disease must provide the impetus for social and legislative change. Our thinking of Alzheimer's disease cannot be the same again" followed by the reference "J. Scott Lancet 342, 1993".

Let me expand on this statement. I also said: "It is not often that a scientific discovery points the need for social change. The finding that a common genetic variant of apolipoprotein E (apoE4) confers a high probability that an individual will develop late-onset Alzheimer's disease is such a discovery ..... We have to consider urgently what we should do about such discoveries. The ethical, legal, psychological and social implications of this discovery must force us towards a new responsibility."

I am on the public record (The Guardian and the BBC Radio 4 Tonight programme) in stating that I do not believe that this test should be generally used. My reasons are in line with similar recommendations for Huntington's chorea. There is no treatment at present for either of these conditions and guidelines to protect the individual from injudicious genetic testing are not clearly established. Therefore there can be very few indications for performing such a test. Exceptions may be that the test could be valuable in the diagnosis of Alzheimer's, but the test should be performed only with informed consent and counselling of the relatives of a demented individual, because a positive result would have serious long-term implications for at-risk relatives. Also if an individual were to insist on testing because of familial risk, then with counselling, this might be appropriate. With these caveats, I do not believe that this test should be made generally available. Therefore my name should not be used to advertise this test.

James Scott

Department of Medicine,

Royal Postgraduate Medical School,

Du Cane Road,

London W12 ONN, UK

\section{Canopy network}

SIR - We established the Canopy Research Network (CRN) in July with a two-year planning grant from the Database Activities Program and the Ecosystems Program of the National Science Foundation to establish methods to collect, store, analyse, interpret and display three-dimensional data relating to tree crowns and forest canopies. We are now soliciting input from researchers in other fields who have developed techniques relevant to the complex threedimensional structure of tree crowns and forest canopies.

Over the next years, we plan: (1) to compile an array of research questions requiring information on canopy structure; (2) to examine useful information models and software tools in use in allied fields; and (3) to develop conceptual models and recommendations for the types and format of information and analyses necessary to answer research questions posed by canopy researchers.

Readers with information about analytical tools that could be applied to this area of research are asked to contact us, either at the CRN e-mail bulletin board at canopy@elwha.evergreen.edu, or at either of the addresses below.

\section{Nalini M. Nadkarni}

Evergreen State College, Lab I,

Olympia, Washington 98585, USA

Fax +1 2068666794

nadkarnn@elwha.evergreen.edu

Geoffrey Parker

Smithsonian Environmental

Research Center,

PO Box 28,

Edgewater, Maryland 21037-0028, USA

Fax +1 3012617954

parker@serc.si.edu

\section{Modest proposal}

SIR - Your leading article "Crime and punishment" (Nature 365, 591; 1993) makes the convicting of innocent people for crimes of terrorism seem irrational as well as illegal and immoral. It is not.

If only the guilty are punished, an Irishman in England will be safe if he does not plant bombs. If innocent Irishmen are punished after a bombing, the only way an Irishman can be safe is to get bombers arrested before their bombs go off. This puts pressure on the entire Irish community to be informers.

Random punishment generates the same compulsion to inform as does collective punishment. Such methods appeal to counter-terrorist forces, and maybe they sometimes work, but prominent devotees have come to bad ends.

Charles W. McCutchen

5213Acacia Avenue,

Bethesda, Maryland 20814, USA 